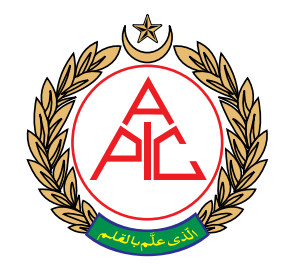

${ }^{1}$ Assistant Professor of Anesthesiology, School of Medicine, Ilam University of Medical Sciences, Ilam, (Iran)

${ }^{2}$ Assistant Professor of Cardiology, School of Medicine, School of Medicine, Ilam University of Medical

Sciences, Ilam, (Iran)

${ }^{3}$ Department of Nursing,

Faculty of Nursing and

Midwifery, Bam University of

Medical Sciences, Bam, (Iran)

${ }^{4}$ Department of Nursing,

Faculty of Nursing and

Midwifery, Ilam University of

Medical Sciences, Ilam, (Iran)

${ }^{5}$ Student Research Committee

Ilam University of Medical

Sciences, Ilam, (Iran)

${ }^{6}$ Department of Nursing,

Faculty of Nursing and

Midwifery, Kermanshah

University of Medical Science,

Kermanshah, (Iran)

${ }^{7}$ Student Research Committee Kermanshah University of

Medical Sciences, Kermanshah, (Iran)

Correspondence: Asma

Tarjoman, Student Research committee, Ilam University of Medical Sciences, Ilam, (IR Iran): Tel: +98-918-340-4704;

E-mail: asmatarjoman@yahoo. com

Received: 8 September 2019; Reviewed: 24, 30 September 2019; 6, 7 November 2019;

Revised: 5 November 2019;

Accepted: 12 November 2019

\section{Knowledge, attitudes and barriers pain management by nurses in Iran: A systematic review}

\author{
Ebrahim Khalighi ${ }^{1}$, Askar Soufinia ${ }^{2}$, Lale Solaimanizadeh ${ }^{3}$, \\ Milad Borji ${ }^{4}$, Asma Tarjoman ${ }^{* 5}$, Behrouz Soltany ${ }^{6}$, Hosein Hydaryian ${ }^{7}$
}

\begin{abstract}
Introduction: Pain is a phenomenon that may be experience $d$ every human being. Pain is one of the symptoms of the disease that has negative effects on patients and causes challenges in medical personnel. The aim of the present systematic review was to determine the knowledge, attitude, and pain management status in Iranian nurses.
\end{abstract}

Methodology: This is a systematic review carried out according to systematic review articles checklist (PRISMA). The search was conducted by two researchers separately. In case of inconsistency, the search was examined by a third researchers. In this study, articles that met the inclusion criteria and published between 2000 to June 2019, were included. The search process was carried out in Iranian and international databases. Data were reported in usinga descriptive method using Excel 2007 software.

Result: According to result 180 articles were extracted in the initial search, of which 50 were excluded from the study, and finally 19 articles entered the data extraction phase. The extracted articles were classified into 4 dimensions of knowledge, attitude, and practice in pain management, nurses'understanding of pain management, nurses' problems in pain relief, and the extent of pain management implementation and assessment, which are described as follows.

Conclusion: Nurses' knowledge, attitude, and managementregarding painmanagementis not in an excellent condition and many studies in Iran should include educational interventions for nurses to help improve their knowledge, attitude, and pain management.

Key words: Pain, Knowledge, Attitude, Practice, Nurse, Systematic Review

Citation: Khalighi E, Soufinia A, Solaimanizadeh L, Borji M, Tarjoman A, Soltany B, Hydaryian $\mathrm{H}$. Knowledge, attitudes and barriers to pain management by nurses in Iran: A systematic review. Anaesth pain \& intensive care 2019;23(4):360-369.

DOI: https://doi.org/10.35975/apic.v23i4.1168

\section{INTRODUCTION}

Nursing is a profession that plays an effective role in patient care, ${ }^{1,2}$ and it is important to provide compassionate nursing care. ${ }^{2}$ Nurses cooperate well together and this can improve the health of patients. ${ }^{3}$ One of the prerequisites for such goal is to have the specialized knowledge and knowledge required in nursing. Pain control is among the factors that require specialized knowledge. ${ }^{4,5}$ Pain control is one of the tasks of nurses. ${ }^{6}$ Nurses' pain control can help improve the health of patients and it is essential to improve their knowledge and attitude. ${ }^{7,8}$ In fact, all patients are entitled to pain relief, and one of the challenges for nurses is to ensure patient comfort and relieve pain. ${ }^{9}$

Pain is one of the symptoms of the disease that has 
original article

negative effects on patients and causes challenges in medical personnel. ${ }^{10,11}$ Pain is a phenomenon that may be experience $d$ every human being. ${ }^{12-14}$ So that's the study Den Beuken-Van The prevalence of pain after treatment in cancer patients was $39.3 \%{ }^{15}$ also in the study Mansfield et al.showed prevalence of chronic widespread pain is between $0-24 \%{ }^{16}$ The pain had adverse effects on patients including poor mental health status, ${ }^{17}$ poor quality of life, ${ }^{18}$ and sleep disorders. ${ }^{19}$ Considering these negative effects, it is necessary to identify the factors affectingthe pain management and relief. ${ }^{20-22}$

Despite the great attention paid to the pain management program in nursing education and care programs, there are still challenges in this regard. ${ }^{23}$ So far, various tools have been designed to measure pain in patients or nurses ${ }^{24-26}$ and various studies have measured the knowledge and attitude of nurses and nursing students in this regard; $5,27,28$ however, the results of previous studies have provided different information. So that study showed that nursing students did not have knowledge and attitudes in pain management and assessment. ${ }^{5}$ Ekim, et al showed in a study that the highest score ranged between $15-65 \%$ and needed further training in this area. ${ }^{27} \mathrm{Al}$ Qadire et al. also showed that nurses had a lower level of knowledge than other studies. ${ }^{28}$ The most common factors associated with inappropriate pain management may include nurses' inadequate knowledge level, wrong assessment, shortage of nursing personnel, and fear of side effects of painkillers. ${ }^{29}$

\section{AIM}

Considering the role of nurses in pain control and management, as well as the role of pain in patients' quality of life, it is necessary to have access to sufficient information on knowledge, attitude, and barriers to pain management in nurses. This information can provide the pave the way for deciding o necessary interventions to improve nurses' knowledge, attitude, and barriers to pain management. Therefore, the aim of the present systematic review was to determine the knowledge, attitude, and pain management status in Iranian nurses.

\section{METHODOLOGY}

\section{Study protocol}

This is a systematic review carried out according to systematic review articles checklist (PRISMA). ${ }^{30}$ The search was conducted by two dominant researchers separately in the field of search. In case of inconsistency, the search was examined by a third researchers.

\section{Search strategy}

In this study, articles that met the inclusion criteria and published between 2000 to June 2019, were included. The search process was carried out in Iranian databases such as SID, Regional Information Center for Science and Technology (RICST), MagIran, IranDoc, Barakat Knowledge Network System, Iranian National Library and international databases such as PubMed / Medline, Cochrane Library, Scopus, Science Direct, Web of Sciences, Embase, EBSCO, and Google Scholar. The search was performed using MESH-related English words and their Persian equivalents: "Pain", "Nurse", Knowledge "," Attitude "," Understanding "," Barriers "," Perspective "," Painkiller "," Pain Severity "," Pain control barriers "," Pain assessment "," Non-drug pain control "," Iran "and the above keywords were combined using " AND "and" OR "search strategies. An example of a search strategy in Pubmed is as follows:

(Pain[Title/Abstract]) OR Knowledge[Title/ Abstract]) OR Attitude[Title/Abstract]) OR Understanding[Title/Abstract]) OR Barriers[Title/ Abstract]) OR Perspective[Title/Abstract]) OR Painkiller[Title/Abstract]) OR Pain Severity[Title/ Abstract]) OR Pain Control barriers[Title/Abstract]) OR Pain Assessment[Title/Abstract]) OR Nondrug Pain Control[Title/Abstract]) AND Iran[Title/ Abstract]) AND Nurse[Title/Abstract])

\section{Inclusion criteria:}

Assessment of knowledge, attitude, pain management methods and factors related to the research topic in nurses, availability of full-text articles.

\section{Exclusion criteria:}

Interventional studies, case-control studies, review, qualitative and interventional studies, re-publish studies

\section{Data extraction:}

A checklist including author's name, year of publication, location, sample size, method, questionnaire used, and findings was designed and used.

\section{Statistical analysis:}

Data were reported in using a descriptive method using Excel 2007 software.

\section{RESULTS}

According to Figure 1, Number 80 articles were extracted in the initial search, of which 50 were excluded from the study, and finally 19 articles entered the data extraction phase (Figure 1). The extracted articles were classified into 4 dimensions of knowledge, attitude, and practice in pain management, 


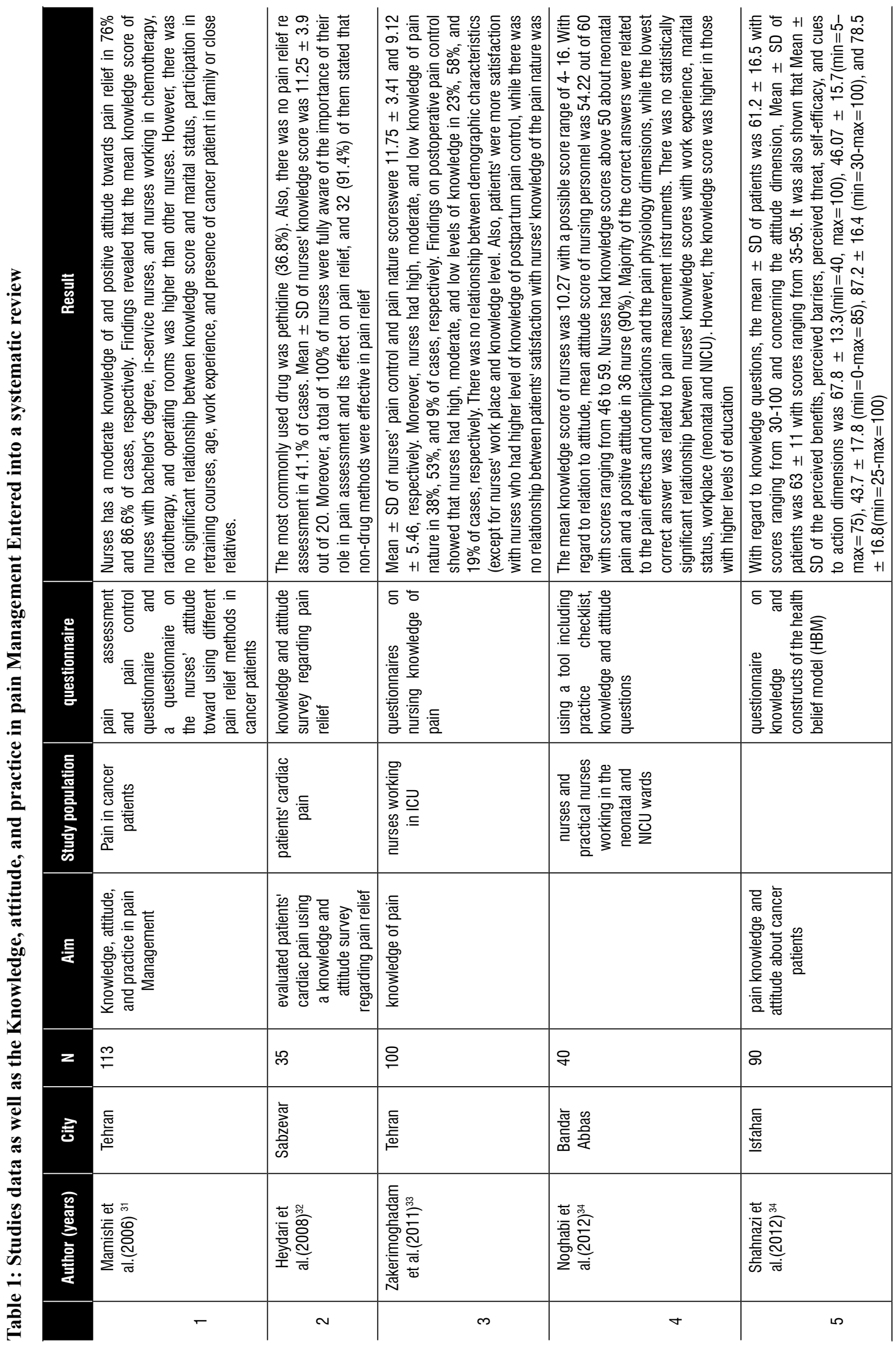


original article
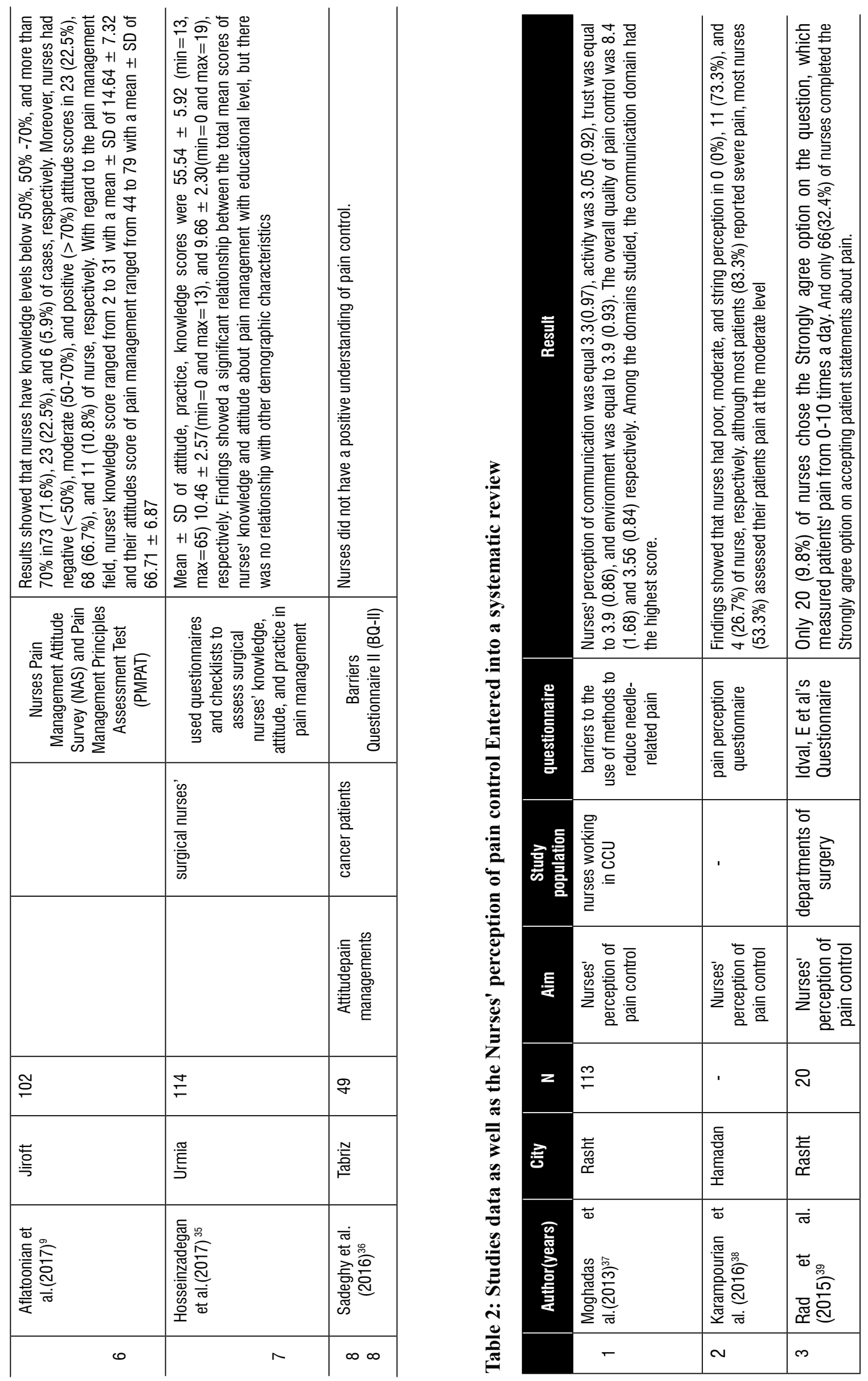


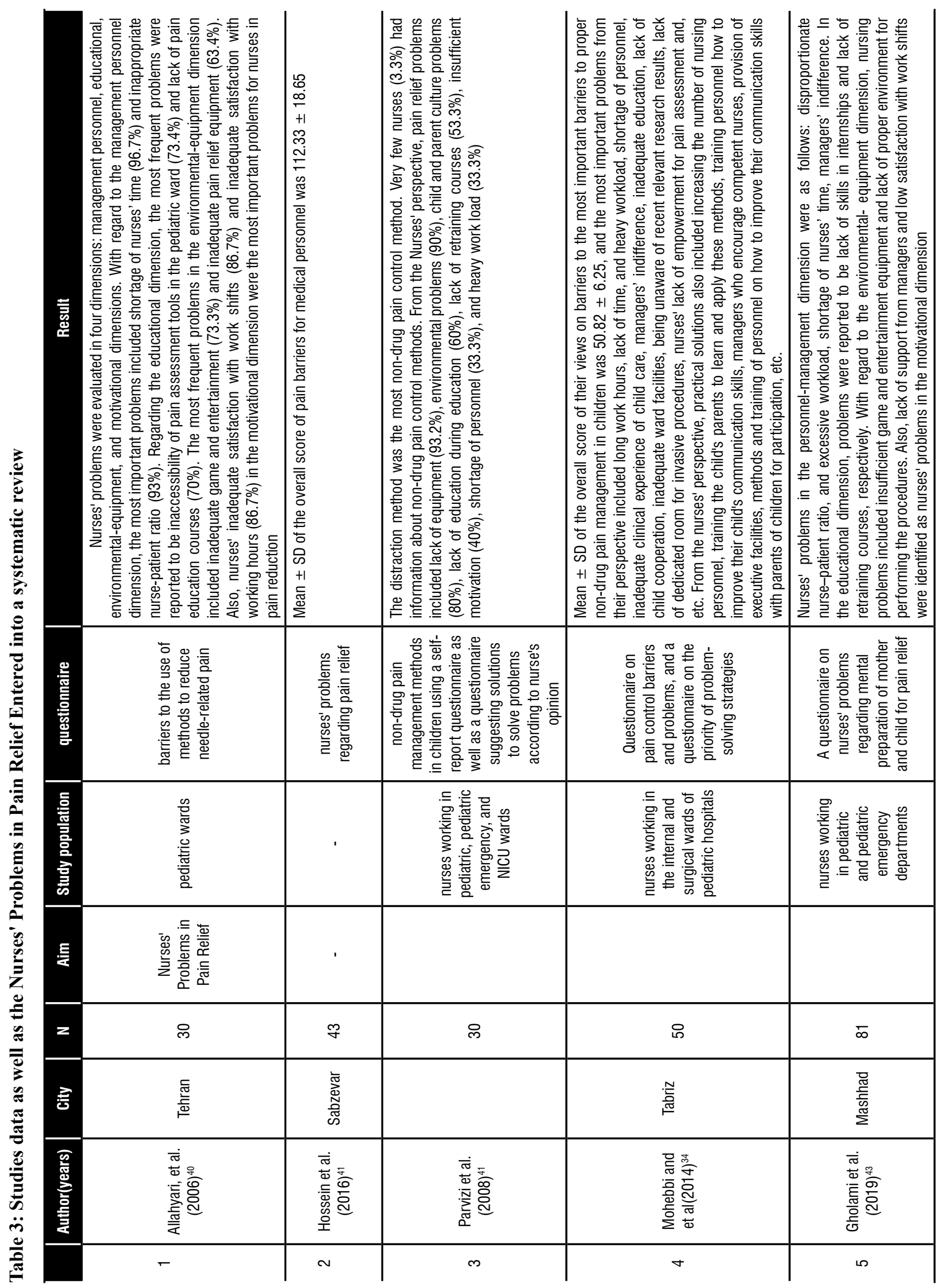


original article

\begin{tabular}{|c|c|c|c|c|c|}
\hline & 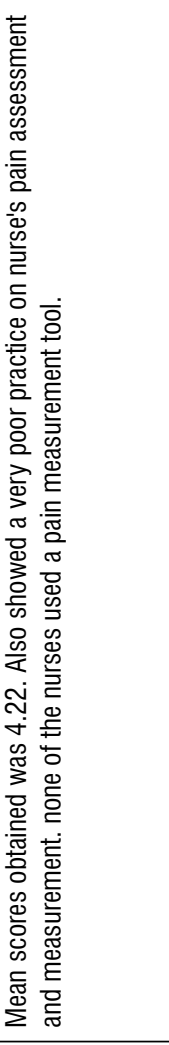 & 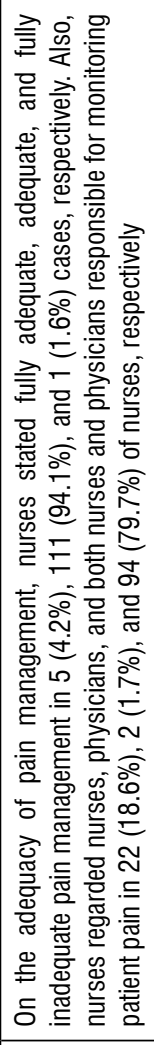 & 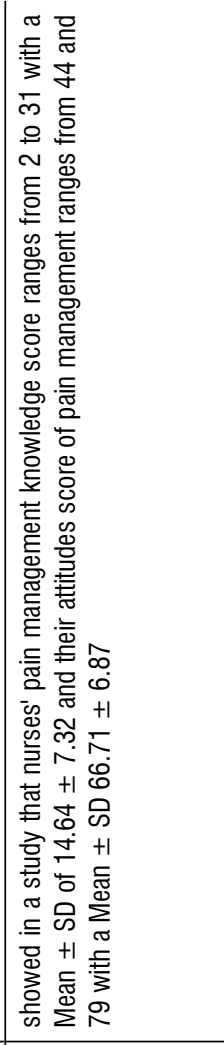 & 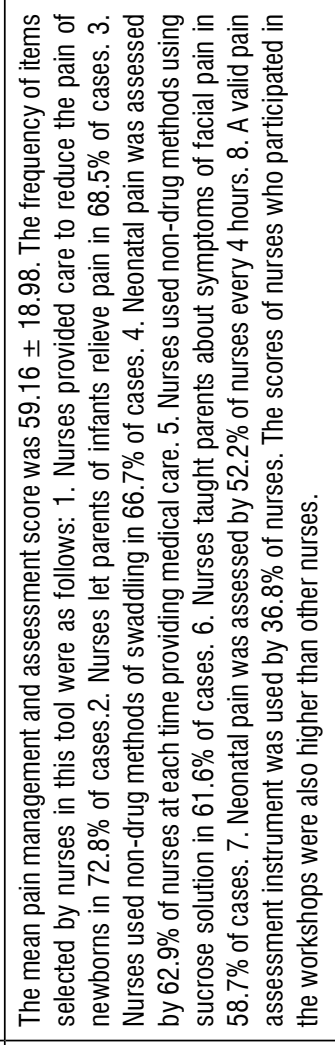 & 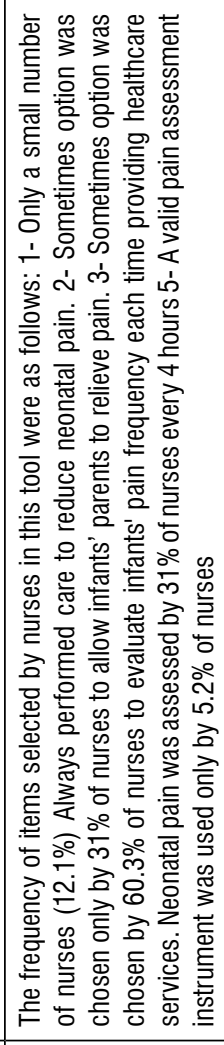 \\
\hline . & 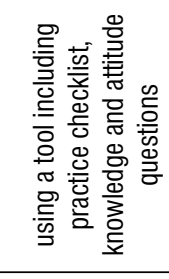 & ' & 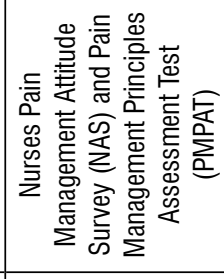 & 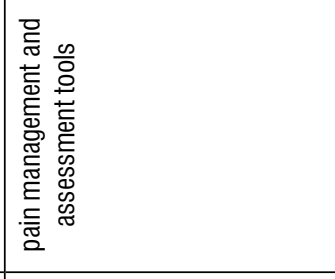 & 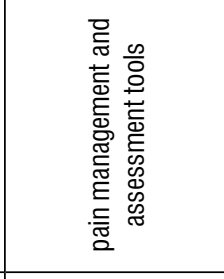 \\
\hline 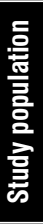 & & 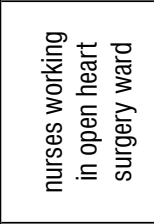 & & 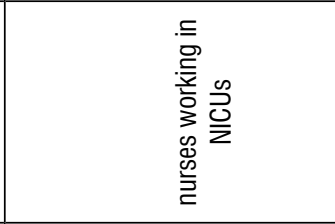 & 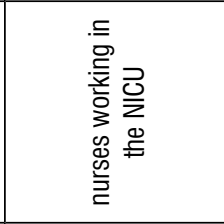 \\
\hline$\frac{E}{2}$ & 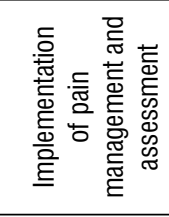 & & & 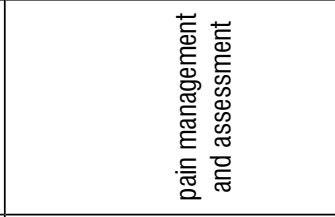 & 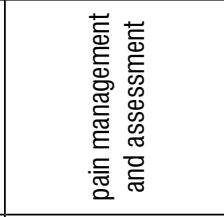 \\
\hline$z$ & q & 요 & $\stackrel{\Upsilon}{\odot}$ & $\stackrel{\infty}{\stackrel{m}{ }}$ & \\
\hline 둔 & 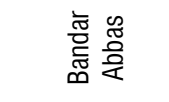 & & 妾 & & $\stackrel{\text { E }}{=}$ \\
\hline 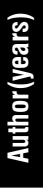 & 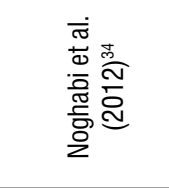 & 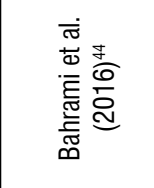 & 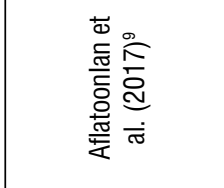 & 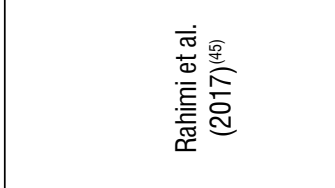 & 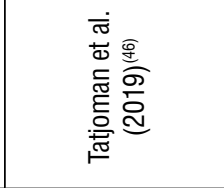 \\
\hline & $\tau$ & $\sim$ & $m$ & $\nabla$ & ما \\
\hline
\end{tabular}




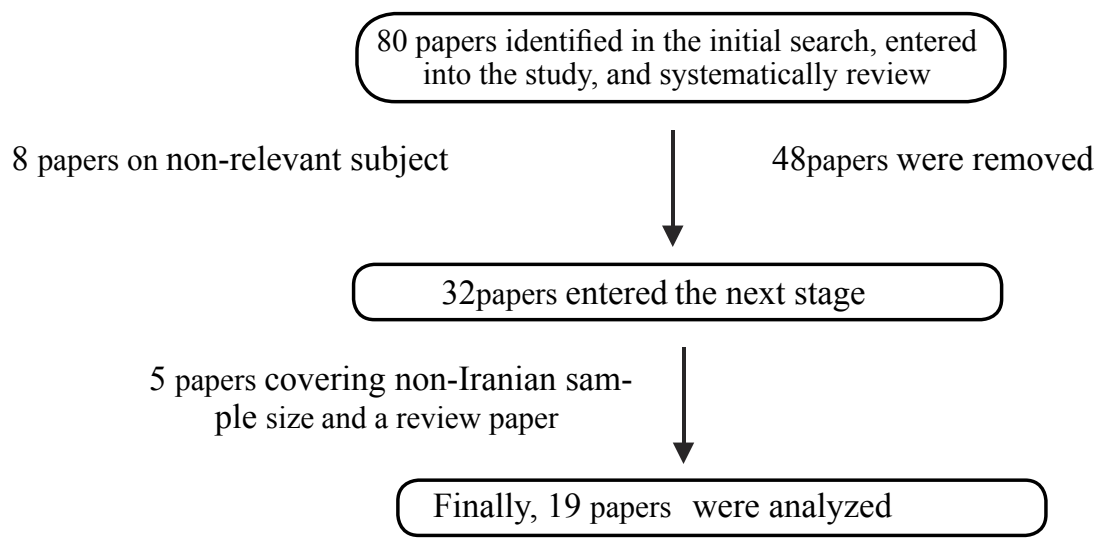

Figure 1: Flowcharts for systematic review

nurses' understanding of pain management, nurses' problems in pain relief, and the extent of pain management implementation and assessment, which are described as follows.

The findings of Table 1 show the status of Knowledge, attitude, and practice in pain management in Iranian nurses. According to the findings of this table, there were 8 studies in this field in which knowledge and attitude about pain management were not in excellent condition.

The findings of Table 2 show the results of studies of nurses' perceptions of pain in Iran. According to the findings, 3 studies were conducted in the Nurses of Rasht and Hamadan, which explained the perception of pain control in the findings of the table.

The findings in Table 3 showed the results of systematic reviews of Problems in Pain Relief. There were 5 articles in this field that showed that nurses' problems were in the studied areas.

The findings in Table 4 showed the results of systematic reviews of Problems in Implementation of pain management and assessment there were 5 articles in this field that showed that nurses' problems were in the studied areas.

\section{DISCUSSION}

Pain affects the health of patients and calls for special attention. ${ }^{47,48}$ The aim of the present systematic review was to determine the knowledge, attitude, and pain management of nurses in Iran. The extracted articles were classified into 4 dimensions of knowledge, attitude, and practice in pain management, nurses' perception of pain control, nurses' problems in pain relief, and frequency of pain management implementation and assessment.
The findings on the knowledge and attitude domain showed varying knowledge and attitude levels ranging from poor to high levels of knowledge and attitude; while the most common most knowledge and attitude scores were at the moderate range. Previous studies on the knowledge and attitude of nurses in Jordan, ${ }^{49}$ Saudi Arabia, ${ }^{25}$ and India ${ }^{50}$ showed that most of them had poor knowledge and attitude, which was inconsistent with the results of the present study. Lui et al. showed in a study in Hong Kong that nurses had a good attitude toward pain management but their practice and attitude were different. ${ }^{51}$ Alnajar et al. revealed in a study that $51.5 \%$ of nurses had a positive attitude toward pain management in cancer patients ${ }^{8}$ which is consistent with the present study.

The findings also showed that another dimension included nurses' problems regarding pain management. The most important areas of nurses' problems included management, educational, environmental-equipment, and motivational dimensions. Shoqirat showed in a qualitative study that nurses 'problems in pain management were classified in two dimensions: patient-related problems (including patient violence, significant number of companions, etc.), and emergency-related problems (including physicians' mastery of pain management and shortage of nursing personnel). Nurses also emphasized the role of environmental factors on pain management. ${ }^{52}$ In the study of in the United States, Czarnecki et al. referred to inadequate physician prescriptions and low priority of pain management as barriers to pain management in nurses. ${ }^{53}$ Pretorius also stated in a study that pain management barriers included unwillingness to prescribe pain relievers, lack of time, heavy workload, and nurses' lack of knowledge of narcotic use, ${ }^{54}$ which is consistent with the present study. 


\section{CONCLUSION}

Nurses' knowledge, attitude, and management regarding pain management is not in an excellent condition and many studies in Iran should include educational interventions for nurses to help improve their knowledge, attitude, and pain management.

Acknowledgment: Student Research Committee, Kermanshah
University of Medical Sciences, Kermanshah, Iran (Grant Number: 3008508).

Conflict of Interests: No conflict of interest was reported.

Authors contribution: All authors took part in literature search, analysis and manuscript preparation.

\section{REFERENCES}

1. Shohani M, Rasouli M, Sahebi A. The level of professional autonomy in Iranian nurses. JCDR. 2018;12(5):LC1-LC4. DOI: 10.7860/ JCDR/2018/31249.11465

2. Dalvandi A, Vaisi-Raygani A, Nourozi K, Ebadi A, Rahgozar M. The importance and extent of providing compassionate nursing care from the viewpoint of patients hospitalized in educational hospitals in Kermanshah-Iran 2017. Open Access Maced J Med Sci. 2019 Mar 28;7(6):1047-52. [PubMed] DOI: 10.3889/oamims.2019.204

3. Zamanzadeh V, Irajpour A, Valizadeh $L$, Shohani $M$. The meaning of collaboration, from the perspective of Iranian nurses: A qualitative study. ScientificWorldJournal. 2014;2014:785942. [PubMed] DOI: 10.1155/2014/785942

4. Peterson $A$, Berggården $M$, Schaller AS, Larsson B. Nurses' advocacy of clinical pain management in hospitals: a qualitative study. Pain Manag Nurs. 2019;20(2):133-9. [P [PubMed] DOI: 10.1016/i.pmn.2018.09.003

5. Hroch J, VanDenKerkhof EG, Sawhney M, Sears N, Gedcke-Kerr L. Knowledge and attitudes about pain management among Canadian nursing students. Pain Manag Nurs. 2019;20(4):382-9. [PubMed] DOI: 10.1016/i.pmn.2018.12.005

6. Colquhoun L, Shepherd V, Neil M. Pain management in new amputees: a nursing perspective. $\mathrm{Br} J$ Nurs. 2019;28(10):638-46. [PubMed] DOI: 10.12968/bjon.2019.28.10.638
7. Holtzman AL, Williams JP, Hutchinson DF, Morris CG, Yeung AR. Improving patient-reported pain during radiotherapy through nurse involvement and patient education. Am J Clin Oncol. 2018;41(10):102830. [PubMed] DOI: 10.1097/ C0C.0000000000000415

8. Alnajar MK, Darawad MW, Alshahwan SS, Samarkandi OA. Knowledge and attitudes toward Cancer pain management among nurses at oncology units. J Canc Educ. 2019;34(1):186-93. [PubMed] DOI: 10.1007/s13187-017-1285-5

9. Aflatoonian MR, Rafati F. The survey of nurses, knowledge and attitude towards pain management in Jiroft University of medical sciences. JAP. 2017;8(2):14-21. [Free Full Text]

10. Fernandes MdeF, Komessu JH. Nurses' challenges in view of the pain and suffering of families of terminal patients. Rev Esc Enferm USP. 2013;47(1):250-7. [PubMed] DOl: $10.1590 / \mathrm{S} 0080-$ $\underline{62342013000100032}$

11. Mohammadi $M$, Raiegani $A A V$, Jalali $R$, Ghobadi A, Salari N. The prevalence of low back pain among Iranian hospital nurses: A systematic review and metaanalysis. Nursing Midwifery Studies. 2019;8(1):1-6. DOI: 10.4103/nms. nms 46_18

12. Ganasegeran $\mathrm{K}$, Abdulrahman $\mathrm{SA}$, Al-Dubai SAR, Tham SW, Perumal M. Spirituality needs in chronic pain patients: a cross-sectional study in a general hospital in Malaysia. J Relig Health. 2018:1-16. [PubMed] DOI: 10.1007/s10943-018-0730-z

13. Vasigh $A$, Jaafarpour $M$, Khajavikhan $J$, Khani $A$. The effect of gabapentin plus celecoxib on pain and associated complications after laminectomy. J Clin Diagn Res. 2016;10(3):UC048. [PubMed] DOI: 10.7860/ $\underline{\mathrm{JCDR} / 2016 / 17923.7346}$

14. Soltanzadeh M, Ebad A, Pipelzadeh M, Tabatabaei S, Dehghani FM, Vasigh A, et al. Gabapentin may relieve postcoronary artery bypass graft pain: a double blind randomized clinical trial. Iran Cardiovasc Res J. 2011;5(3):7982. [Free Full Text]

15. Van Den Beuken-Van MH, Hochstenbach LM, Joosten EA, TjanHeijnen VC, Janssen DJ. Update on prevalence of pain in patients with cancer: systematic review and meta-analysis. J Pain Symptom Manage. 2016;51(6):1070-90. e9. [PubMed] DOI: 10.1016/i. ipainsymman.2015.12.340

16. Mansfield KE, Sim J, Jordan JL, Jordan KP. A systematic review and meta-analysis of the prevalence of chronic widespread pain in the general population. Pain. 2016;157(1):5564. [PubMed] DOI: 10.1097/i. pain. 0000000000000314

17. Demyttenaere K, Bruffaerts R, Lee S, Posada-Villa J, Kovess V, Angermeyer $\mathrm{MC}$, et al. Mental disorders among persons with chronic back or neck pain: results from the World Mental Health Surveys. Pain. 2007;129(3):332-42. [PubMed] DOI: 10.1016/i.pain.2007.01.022

18. Strand EB, Mengshoel AM, Sandvik L, 
Helland IB, Abraham S, Nes LS. Pain is associated with reduced quality of life and functional status in patients with myalgic encephalomyelitis/chronic fatigue syndrome. Scand J Pain. 2019;19(1):61-72. [PubMed] DOI: 10.1515/sipain-2018-0095

19. Martinez-Martin $P$, Rizos AM, Wetmore JB, Antonini A, Odin P, Pal S, et al. Relationship of nocturnal sleep dysfunction and pain subtypes in parkinson's disease. Mov Disord Clin Pract 2019;6(1):57-64. [PubMed] DOI: $10.1002 / \mathrm{mdc} 3.12694$

20. Papathanassoglou ED, Hadjibalassi $M$, Miltiadous $P$, Lambrinou $E$, Papastavrou E, Paikousis L, et al. Effects of an integrative nursing intervention on pain in critically ill patients: a pilot clinical trial. Am J Crit Care. 2018;27(3):172-85. [PubMed] DOl: $10.4037 / a j c c 2018970$

21. Drake G, de C Williams AC. Nursing education interventions for managing acute pain in hospital settings: a systematic review of clinical outcomes and teaching methods. Pain Manag Nurs. 2017;18(1):3-15. [PubMed] D0I: 10.1016/j.pmn.2016.11.001

22. Bastami M, Azadi A, Mayel M. The use of ice pack for pain associated with arterial punctures. J Clin Diagn Res. 2015 Aug;9(8):JC07-9. [PubMed] D0I: 10.7860/JCDR/2015/12657.6336

23. Duke G, Haas BK, Yarbrough $S$, Northam S. Pain management knowledge and attitudes of baccalaureate nursing students and faculty. Pain Manag Nurs. 2013;14(1):11-9. [PubMed] DOI: 10.1016/i.pmn.2010.03.006

24. Shohani M, Tavan H. The validity and reliability of the constructs of pain management-measuring tool for incurable patients. Iran Red Crescent Med J. 2018;20(9):e62353. DOl: 10.5812/ircmj.62353.

25. Alotaibi K, Higgins I, Chan S. Nurses' knowledge and attitude toward pediatric pain management: a crosssectional study. Pain Manag Nurs. 2019;20(2):118-25. [PubMed] DOI: 10.1016/i.pmn.2018.09.001

26. Dale CM, Prendergast V, Gélinas C,
Rose L. Validation of The Criticalcare Pain Observation Tool (CPOT) for the detection of oral-pharyngeal pain in critically ill adults. Crit Care Med. 2018;48:334-8. [PubMed] DOI: 10.1016/i.jcrc.2018.09.024

27. Ekim A, Ocakcl AF. Knowledge and attitudes regarding pain management of pediatric nurses in Turkey. Pain Manag Nurs. 2013;14(4):e262-e7. [PubMed] DOI: $\quad 10.1016 / \mathrm{j}$. pmn.2012.02.004

28. Al Qadire M, Al Khalaileh M. Jordanian nurses knowledge and attitude regarding pain management. Pain Manag Nurs. 2014;15(1):220-8. DOl: 10.1016/.jpmn.2012.08.006

29. Mercadante S. Why are our patients still suffering pain? Nature Clin Oncol. 2007;4(3):138-9.

30. Moher D, Liberati A, Tetzlaff J, Altman DG. Preferred reporting items for systematic reviews and metaanalyses: the PRISMA statement. Ann Intern Med. 2009;151(4):264-9. [PubMed] DOl: 10.7326/0003-4819151-4-200908180-00135

31. Mamishi N, Behroozishad F, Mohagheghi M, Eftekhar Z, Shahabi Z. The study of nurses' knowledge and attitudes regarding cancer pain management. Hayat. 2006;12(2):2332. [Free Full Text]

32. Heydari A, Najjar L, Estagi Z. The role of nurses in pain management of coronary heart diseases in Sabzevar, Iran. J GUMS. 2008;10(2):59-64.

33. Zakerimoghadam $M$, Shariat $E$, Asadi Noughabi AA, Mehran A, Soghrati V. Relationship between nurses' knowledge about pain and satisfaction of pain relieving procedures among postoperative CABG patients. Hayat. 2011;17(3):49-58. [Free Full Text]

34. Noghabi A, Soudagar S, Nazari 0. Knowledge, attitude and performance of nurses regarding pain assessment and measurement, Bandar Abbas, Iran. Hormozgan Med J. 2012;16(5):40313.

35. Hosseinzadegan F, Jasemi M, Shahbaz A. Survey of nurse's knowledge, attitude and practice in surgery wards toward assessment and management of patients's pain in teaching hospitals of urmia in 2016. J Urmia Nurs Midwifery Fac. 2017;15(8):620-9.

36. Sadeghy A, Mohamadian R, Rahmani A, Fizollah-zadeh $\mathrm{H}$, Jabarzadeh $\mathrm{F}$, Azadi $A$, et al. Nurse attitude-related barriers to effective control of cancer pain among Iranian nurses. Asian Pac J Cancer Prev. 2016;17(4):21414. [PubMed] DOl: 10.7314/ APJCP.2016.17.4.2141

37. Moghadas T, Baghaei M, Kazemnezhad E, Momeni M, SedghiSabet M. Comparison of the nurse's and patient's perception on quality of pain control in patients under coronary artery bypass graft. J Health Care. 2013;15(4):19-29. [Free Full Text]

38. Karampourian A, Imani B, Mousavi-Bahar SH, Mahzad R. Comparison of nurses, patient and surgeon perception of pain and its relationship with analgesics at post open prostatectomy. J Res Urol. 2016;1(1):1-7. [Free Full Text]

39. Rad TK, Sayad S, Baghaei M, Hossini SM, Salahshorian A, Zare M. A study of patients and nurses' perception of the quality of pain management in the patients undergoing surgery in the departments of surgery of rasht hospitals in 2013. Glob J Health Sci. 2015;7(7):55. [PubMed] DOI: 10.5539/gihs.v7n7p55

40. Allahyari I, Alhany F. Evaluation of the nurses' problems in using methods to reduce injection pain in children. Iranian J Pediatrics. 2006;16(2):1838.

41. Hosseini SH, Azizi M. Analysis of "family institution" advocatory policies in islamic republic of iran. Woman and Family Studies. 2016;4(1):7-34. [Free Full Text]

42. Parvizi F, Alhani F, Aghebati N. The nurses' problems in applying nonpharmacological pain management for children. IJNR. 2008;3(9):85-92. [Free Full Text]

43. Gholami S, Tayebi V, Hamedi A, Ghorbanzadeh M. Problems of nurses in using the methods of psychological preparation of the child and the mother before the painful procedures. J Urmia 
Nurs Midwifery Fac. 2019;17(3):17682. [Free Full Text]

44. Bahrami $M$, Saadati $M$, Saadati A, Barati M. A study of patients and nurses' perception of pain management after cardiac surgery. JHC. 2016;18(3):179-90. [Free Full Text]

45. Rahimi 0, Godarzi Z, Khalessi N, Soleimani F, Mohamadi N, Shamshiri A. The implementation of pain management and assessment in neonatal intensive care units of teaching hospitals affiliated to Tehran University of Medical Sciences. JBUMS. 2017;19(6):28-34. [Free Full Text]

46. Tarjoman A, Vasigh A, Safari S, Borji $M$. Pain management in neonatal intensive care units: A cross sectional study of neonatal nurses in llam City. J Neonatal Nurs. 2019;25(3):136-8. DOI: 10.1016/j.jnn.2018.08.006

47. Enteshari-Moghaddam $A$, Isazadehfar K, Habibzadeh A, Hemmati M. Efficacy of methotrexate on pain severity reduction and improvement of quality of life in patients with moderate to severe knee osteoarthritis. Anesth Pain Med. 2019;9(3):e89990. [PubMed] D0I: 10.5812/aapm.89990

48. Rostami K, Sharif F, Zarshenas L, Ebadi A, Farbood A. Health needs in patients suffering from chronic back pain: a qualitative study. Anesth Pain Med. 2019;9(2):e85244. [PubMed] DOI: $10.5812 /$ aapm.85244

49. Khalil $\mathrm{H}$, Mashaqbeh $\mathrm{M}$. Areas of knowledge deficit and misconceptions regarding pain among jordanian nurses. Pain Manag Nurse. 2019;20(6):649-55. [PubMed] DOl: 10.1016/i.pmn.2019.02.010

50. Dongara $A R$, Shah SN, Nimbalkar SM, Phatak AG, Nimbalkar AS. Knowledge of and attitudes regarding postoperative pain among the pediatric cardiac nursing staff: An Indian experience. Pain Manag Nurse. 2015;16(3):314-20. [PubMed] DOl: 10.1016/j.pmn.2014.08.009

51. Lui LY, So WK, Fong DY. Knowledge and attitudes regarding pain management among nurses in Hong Kong medical units. J Clin Nurs. 2008;17(15):201421. [PubMed] DOI: 10.1111/i.13652702.2007.02183.x

52. Shoqirat $N$, Mahasneh $D$, Singh C, AL-Sagarat AY, Habashneh S. Barriers to nursing pain management in the emergency department: A qualitative study. Int J Nurs Pract. 2019;25(5):e12760. [PubMed] DOI: $\underline{10.1111 / \text { iin. } 12760}$

53. Czarnecki ML, Guastello A, Turner HN, Wrona SK, Hainsworth KR. Barriers to pediatric pain management: a brief report of results from a multisite study. Pain Manag Nurse. 2019;20(4):3058. [PubMed] DOI: 10.1016/i. pmn.2019.01.008

54. Pretorius A, Searle J, Marshall B. Barriers and enablers to emergency department nurses' management of patients' pain. Pain Manag Nurse. 2015;16(3):372-9. [P [PubMed] DOI: 10.1016/i.pmn.2014.08.015 